\title{
Embryo development and establishment of pregnancy after embryo transfer in pigs: coping with limitations in the availability of viable embryos
}

\author{
T. J. King ${ }^{1}$, J. R. Dobrinsky², J. Zhu ${ }^{1}$, H. A. Finlayson ${ }^{1}$, W. Bosma ${ }^{1}$, \\ L. Harkness ${ }^{1}$, W. A. Ritchie ${ }^{1}$, A. Travers ${ }^{1}$, C. McCorquodale ${ }^{1}$, \\ B. N. Day ${ }^{3}$, A. Dinnyés ${ }^{1}$, P. A. De Sousa ${ }^{1}$ and I. Wilmut ${ }^{1 *}$ \\ ${ }^{1}$ Department of Gene Expression and Development, Roslin Institute (Edinburgh), Roslin, \\ Midlothian, Edinburgh EH25 9PS, UK; ${ }^{2}$ Germplasm \& Gamete Physiology Laboratory, ARS, \\ US Department of Agriculture, Beltsville, MD 20705, USA; and ${ }^{3}$ Animal Science Unit, \\ University of Missouri, College of Agriculture, Animal Sciences Centre, Columbia,
} MO 65211, USA

Embryo transfer and pregnancy maintenance strategies in pigs were evaluated with reference to situations in which limited numbers of viable embryos or micromanipulated embryos are available, such as pig cloning. Development of embryos with compromised zona pellucida was compared with development of embryos with intact zona pellucida. Micromanipulation had no effect on blastocyst production rates after development in vivo or in vitro, but development in vivo improved the number of embryos reaching the blastocyst stage. Transfer of embryos with compromised zona pellucida resulted in live piglets. Several hormone treatments to maintain pregnancy were tested in a model in which three embryos were transferred into unmated recipient gilts, compared with transfer of three embryos into mated recipients. None of the hormonal treatments resulted in pregnancy rates of more than $25 \%$ at term and no more than $9 \%$ of transferred embryos survived, in comparison with $50 \%$ of the mated recipients successfully carrying $25 \%$ of transferred embryos. Lastly, the developmental potential of parthenogenetic embryos was assessed and $62 \%$ of transferred embryos resulted in pregnancies, none of which continued beyond day 55 of gestation. After co-transfer of three fertilized embryos with 55-60 parthenogenetic embryos into each of six recipients, two live piglets were delivered. The results from the present study indicate that transfer of zona pellucida compromised embryos can yield litters of normal piglets. In addition, it was demonstrated in a model system involving the transfer of three fertilized embryos into mature gilts that hormonal pregnancy maintenance strategies support a low proportion of embryos to term. Lastly, the present study shows for the first time a comparably effective but novel alternative for pregnancy maintenance in the pig involving the co-transfer of parthenote embryos.

\section{Introduction}

Nuclear transfer of somatic cells and other biotechnologies applied to embryo production in vitro yield very few embryos that are competent to become live offspring. Multiple factors can cumulatively impinge on embryonic competence, including methods for the induction of ovulation, in vitro maturation (IVM), fertilization, culture, nuclear transfer, gene injection, cryopreservation and transfer. In general, minimization of in vitro handling associated with these procedures is likely to be beneficial to subsequent development. This is especially true for pig gametes and embryos, as the techniques are less well developed for this species (Nagashima et al., 1995; Wang et al., 1998, 1999; Dobrinsky et al., 2000).

*Correspondence

Email: lan.Wilmut@bbsrc.ac.uk
Several groups have reported the production of viable piglets after nuclear transfer of somatic cells (Betthauser et al., 2000; Onishi et al., 2000; Polejaeva et al., 2000). Interestingly, all of these groups transferred cloned embryos to final recipients before embryonic compaction. Although piglets were produced, the proportion of embryonic loss directly due to early transfer is unknown. In early studies in mice and sheep, transfer of precompacted embryos with disrupted zonae pellucidae resulted in embryonic loss (Modlinski, 1970; Bronson and McClaren, 1970; Trounson and Moore, 1974). Transfer of zona pellucida-free rabbit blastomeres also results in embryonic loss (Moore et al., 1968). However, nuclear transfer rabbit embryos can survive immediate oviductal transfer (Collas and Robl, 1990; Stice and Robl, 1998). The mechanism by which embryos are lost remains unclear, although it has been speculated that the loss reflects immunological attack (Moore et al., 1968). The objective of the first experiment in 
the present study was to evaluate the developmental competence of precompacted pig embryos with a compromised zona pellucida.

After transfer of micromanipulated embryos, recognition and maintenance of pregnancy play key roles in the production of live offspring. As a polytocous species, maintenance of pregnancy in the pig is dependent on a minimum fetal occupancy within the uterus. This is most critical between approximately day 11 and day 12 of gestation, when conceptus-derived oestrogen is responsible for maternal recognition of pregnancy (Geisert et al., 1990). During this time, a minimum of four to five viable embryos (Polge et al., 1996) or at least 50\% uterine occupancy (Geisert et al., 1990) is required for pregnancy maintenance. This requirement ends by day 14, after which the number of embryos remaining is less critical (Dzuik, 1985). Thus, fewer than four embryos are unable to completely overcome the luteolytic influence normally exerted by a non-pregnant uterus. On the basis of among other factors the timing of conceptus signalling (Geisert et al., 1992) at least two approaches could be used to assist with the pregnancy recognition and maintenance. First, exogenous oestrogen, which acts by altering the release of prostaglandins by the uterus (Frank et al., 1997), could be administered at timed intervals between approximately day 11 and day 15 of gestation (Geisert et al., 1990). Alternatively, accessory corpora lutea could be induced by administration of eCG and hCG on day 9 and day 12 of pregnancy, respectively (Christenson and Day, 1971; Ellicot et al., 1973). This second population of corpora lutea would be refractory to the luteolytic effects of prostaglandin released at about day 14 of the original oestrous cycle and provide a continuing source of progesterone to support pregnancy (Bazer et al., 1982).

A novel pregnancy maintenance strategy, which has not been reported to date, would involve the co-transfer of a limited number of viable embryos of interest with a developmentally inferior embryo capable of contributing to maternal recognition of pregnancy. A suitable co-transfer candidate for such a role would be a parthenogenetic embryo (parthenote), the development of which is completely reliant on maternal genetic information. In support of this proposal, parthenote bovine embryos have been shown to extend the oestrous cycle (Fukui et al., 1992). Until recently, very little was known about the capacity of parthenote pig embryos to develop in vivo. The first report was by Jollif and Prather (1997), in which a filamentous stage conceptus with an intact embryonic disc was recovered 14 days after activation. Advanced fetal development to days 21 and 29 of gestation is now known to be possible after electrical activation of oocytes (Kobayashi et al., 2000; Zhu et al., 2000), and the resulting fetuses have both limb buds and beating hearts.

In the present study, the effects of micromanipulation on early embryonic development in pigs were evaluated. In addition, the study incorporated methods for coping with limitations in the number of developmentally viable embryos.

\section{Materials and Methods}

This study was conducted following approval by Roslin Institute's Animal Ethics Committee and within a project licence issued under the Animal (Scientific Procedures) Act 1986.

The first objective of this study was to evaluate the developmental competence of precompacted pig embryos with a compromised zona pellucida. The second objective was to assess the ability of hormonal treatments to maintain pregnancies with sub-optimal numbers of viable embryos present and the third objective was to evaluate the potential for parthenogenetic embryos to support pregnancy when co-transferred with three fertilized embryos.

Experiment 1 compared the development of untreated day 2 (two- to four-cell) embryos with zona pellucida compromised (ZC) embryos, mimicking the effect of an enucleation procedure for mature pig oocytes (De Sousa et al., in press). Development to the blastocyst stage after culture in vitro or in vivo was compared. Further development in vivo was then compared after oviductal transfer of zona pellucida intact (ZI) or ZC embryos to synchronous recipient gilts. All pregnancies were monitored by ultrasonography throughout gestation to term.

Experiment 2 evaluated the success of four hormonal strategies for maintaining pregnancy after embryo transfer. Two regimens were based on oestradiol treatment in early gestation whereas the other two were based on production of accessory corpora lutea. The regimens were tested in a model in which three embryos were transferred into the uterus of non-pregnant recipient gilts before treatment. These treatments were compared with a group that received three embryos and no hormonal treatment (control) and another group in which three embryos were transferred into mated recipients and, therefore, already contained a number of fertilized embryos.

Experiment 3 evaluated the potential for parthenogenetic embryos to establish pregnancies that were monitored by ultrasonography throughout their development. In addition, the maintenance of pregnancy to term was evaluated when three fertilized embryos were co-transferred with parthenogenetic embryos into non-pregnant gilts.

\section{Embryo production}

Embryos were produced from Large White gilts that were approximately 9 months of age or older and weighed at least $120 \mathrm{~kg}$ at the time of use. Donor gilts were mated twice at $6 \mathrm{~h}$ intervals with either a Large White or Meishan boar either after signs of a natural oestrus, which may have been synchronized by feeding $20 \mathrm{mg}$ altrenogest (Regumate; Hoechst Roussel Vet. Ltd, Milton Keynes) each day for 18 days, or after oestrus generated after superovulation. Superovulation was achieved by feeding, between day 11 and day 15 after an observed oestrus, $20 \mathrm{mg}$ altrenogest once a day for 4 days, followed by $20 \mathrm{mg}$ altrenogest twice a day on day 5. On day 6, 1500 iu eCG (PMSG; Intervet UK Ltd, Cambridge) was injected at 
20:00 h and 83 h later 750 iu hCG (Chorulon; Intervet UK Ltd) was injected.

\section{Embryo culture, manipulation and surgical recovery}

Unless otherwise noted, all chemical reagents used during oocyte and embryo culture and micromanipulation were purchased from Sigma (Poole, Dorset). The base medium used for embryo culture at $39^{\circ} \mathrm{C}$ in $5 \% \mathrm{CO}_{2}$ in air was NCSU23 (Petters and Wells, 1993), comprising $108.73 \mathrm{mmol} \mathrm{NaCl} \mathrm{I}^{-1}, 4.78 \mathrm{mmol} \mathrm{KCl} \mathrm{I}^{-1}, 1.7 \mathrm{mmol} \mathrm{CaCl}_{2}$ $\mathrm{I}^{-1}, 1.19 \mathrm{mmol} \mathrm{MgSO}_{4} \mathrm{I}^{-1}, 25.07 \mathrm{mmol} \mathrm{NaHCO}_{3} \mathrm{I}^{-1}$, $1.19 \mathrm{mmol} \mathrm{KH}_{2} \mathrm{PO}_{4} \mathrm{I}^{-1}, 5.55 \mathrm{mmol}$ glucose $\mathrm{I}^{-1}, 1.0 \mathrm{mmol}$ glutamine $\mathrm{I}^{-1}, 7.0 \mathrm{mmol}$ taurine $\mathrm{I}^{-1}, 5 \mathrm{mmol}$ hypotaurine $\mathrm{I}^{-1}$, 0.4\% BSA-V (A-7906, Sigma), 100.0 iu Penicillin-G I-1, 50.0 mg streptomycin $\mathrm{I}^{-1}$. Embryos were cultured in $500 \mu \mathrm{l}$ of medium at $39^{\circ} \mathrm{C}$ in $5 \% \mathrm{CO}_{2}$ in air. The base medium for embryo manipulation was Hepes-buffered NCSU23 (hbNCSU23), comprising $131.7 \mathrm{mmol} \mathrm{NaCl} \mathrm{I}{ }^{-1}, 4.78 \mathrm{mmol}$ $\mathrm{KCl} \mathrm{I}^{-1}, 1.7 \mathrm{mmol} \mathrm{CaCl}_{2} \mathrm{I}^{-1}, 1.19 \mathrm{mmol} \mathrm{MgSO}_{4} \mathrm{I}^{-1}, 2 \mathrm{mmol}$

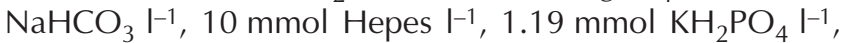
$5.55 \mathrm{mmol}$ glucose $\mathrm{I}^{-1}, 1.0 \mathrm{mmol}$ glutamine $\mathrm{I}^{-1}, 12.0 \mathrm{mmol}$ taurine $\mathrm{I}^{-1}$, 0.4\% BSA-V, 100.0 iu Penicillin $\mathrm{G} \mathrm{I}^{-1}$ and $50 \mathrm{mg}$ streptomycin $\mathrm{I}^{-1}$. The medium used for embryo recovery was hb-NCSU23 or MR-025-D FHM (Hepes-buffered medium supplied by Cell and Molecular Technologies, Lavallette, NJ).

Embryos required for Expts 1-3 were recovered surgically from mated donors by mid-line laparotomy under general anaesthesia, either on day 2 (1 and 3) or days 6-7 (2) of oestrus (oestrus = day 0 ). Anaesthesia was achieved by administering a pre-anaesthetic sedative of $5 \mathrm{mg}$ ketamine $\mathrm{kg}^{-1}$ (Vetalar V; Pharmacia and Upjohn Animal Health Ltd, Corby) and $1 \mathrm{mg}$ azaperone $\mathrm{kg}^{-1}$ (Stresnil; Jansenn Animal Health, High Wycombe) by i.m. injection. This treatment was followed $15 \mathrm{~min}$ later by an i.v. injection of $2 \mathrm{mg}$ ketamine $\mathrm{kg}^{-1}$ and $0.04 \mathrm{mg}$ hypnovel $\mathrm{kg}^{-1}$ (Midazolam; Roche Products Ltd, Welwyn Garden City). Pigs were then intubated and anaesthesia was maintained using oxygen, nitrous oxide and halothane (Halothane-Vet; Merial Animal Health Ltd, Harlow). In Expt 1, the zona pellucida of half of the embryos from each donor was pierced using a glass pipette with an $18 \mu \mathrm{m}$ bore. ZI and ZC embryos from each donor were then allocated in equal numbers to pools destined for different recipient gilts, or maintained in vitro to the blastocyst stage according to donor identity. In all but one of these trials, embryos were distributed equally between both in vivo and in vitro environments. Embryos from 13 of 15 donors were allocated evenly between ZI and ZC groups. Whenever a trial provided sufficient numbers of donor embryos to merit more than one recipient for in vivo development, embryos were allocated in equal numbers among recipients. Embryo transfer to recipient gilts occurred within $3 \mathrm{~h}$ of embryo recovery. Embryos were recovered for analysis 4 days after transfer in Expt 1 after the recipient gilt was killed by i.v. injection of pentobarbitone (Euthatal; Merial Animal Health Ltd) and excision of the reproductive tract. The reproductive tracts were prepared for flushing by trimming off the broad ligament from the oviducts and uterine horns on a warm plate set at $38^{\circ} \mathrm{C}$.

\section{In vitro maturation of oocytes}

Pig ovaries from a local abattoir were collected and maintained at $25-28^{\circ} \mathrm{C}$ in sterile PBS. Ovaries were returned to the laboratory within $2 \mathrm{~h}$ of retrieval, where they were washed and maintained in Dulbecco's PBS (Cat. No BR14, Oxoid, Basingstoke, Hampshire) at $25-28^{\circ} \mathrm{C}$. Follicles (3-8 $\mathrm{mm}$ in diameter) were aspirated within $1 \mathrm{~h}$ using an 18-gauge needle attached to $10 \mathrm{ml}$ syringes. The follicular aspirant was washed three times with 5-10 ml TL-Hepes-PVA (P-8136, Sigma) pre-warmed to $37^{\circ} \mathrm{C}$, with $1-2$ min intervals between washes to allow cumulus-oocyte complexes (COCs) to settle. Washed COCs were then sorted in sterile $60 \mathrm{~mm}$ dishes on stages heated to $37^{\circ} \mathrm{C}$. Only those COCs with at least three complete layers of compact cumulus cells were selected for maturation. Selected COCs were washed three times with fresh TL-Hepes-PVA, followed by passage through $3 \times 500 \mu \mathrm{l}$ drops of NCSU23 modified for oocyte maturation (mNCSU23: $108.73 \mathrm{mmol} \mathrm{NaCl} \mathrm{I-1,} 4.78 \mathrm{mmol}$ $\mathrm{KCl} \mathrm{I}{ }^{-1}, 1.7 \mathrm{mmol} \mathrm{CaCl}_{2} \mathrm{I}^{-1}, 1.19 \mathrm{mmol} \mathrm{MgSO}_{4} \mathrm{I}^{-1}, 25.07$ mmol $\mathrm{NaHCO}_{3} \mathrm{I}^{-1}, 1.19 \mathrm{mmol} \mathrm{KH}_{2} \mathrm{PO} 4 \mathrm{I}^{-1}, 5.55 \mathrm{mmol}$ glucose $\mathrm{I}^{-1}, 1.0 \mathrm{mmol}$ glutamine $\mathrm{I}^{-1}, 7.0 \mathrm{mmol}$ taurine $\mathrm{I}^{-1}$, 5.0 mmol hypotaurine $\mathrm{I}^{-1}$, 100 iu Penicillin-G I-1, $50.0 \mathrm{mg}$ streptomycin $\mathrm{I}^{-1}$ supplemented with $1.0 \mathrm{mmol}$ cysteine $\mathrm{I}^{-1}$ and $5.0 \mathrm{mg}$ insulin $\mathrm{ml}^{-1}$ ). COCs were then matured in groups of 50 in $500 \mu \mathrm{lmNCSU} 23$ containing $10 \mathrm{iu} \mathrm{hCG}$ $\mathrm{ml}^{-1}, 10$ iu eCG $\mathrm{ml}^{-1}$, and $10 \%$ pig follicular fluid for $22 \mathrm{~h}$ at $39^{\circ} \mathrm{C}$, in $5 \% \mathrm{CO}_{2}$ in air. After $22 \mathrm{~h}$, embryos were transferred to mNCSU23 without the presence of hormones for a further $22 \mathrm{~h}$ of culture.

\section{Parthenogenetic activation of oocytes and culture}

Oocytes were activated electrically in $0.3 \mathrm{~mol}$ mannitol $\mathrm{I}^{-1}, 100 \mu \mathrm{mol} \mathrm{MgCl}_{2} \mathrm{I}^{-1}$ and $50 \mu \mathrm{mol} \mathrm{CaCl}_{2} \mathrm{I}^{-1}$ using three pulses of $80 \mu \mathrm{s}$ at $1.0 \mathrm{kV}$ per cm DC after $5 \mathrm{~s}$ at $0.25 \mathrm{kV}$ per $\mathrm{cm}$ AC. This electrical activation was followed by three washes in hb-NCSU23. The formation of the second polar body was suppressed and a diploid DNA content restored by culturing activated eggs in $7.5 \mu \mathrm{g}$ cytochalasin $\mathrm{B} \mathrm{m} \mathrm{m}^{-1}$ in NCSU23 for $6 \mathrm{~h}$. Activated oocytes were washed and incubated overnight in NCSU23 without cytochalasin B. Oocytes were activated 44-46 h after maturation, and both uncleaved and cleaved embryos were transferred into a recipient at 1 day after activation.

\section{Embryo transfer}

Fertilized embryos and parthenotes were transferred after a mid-line laparotomy under general anaesthesia. During surgery, the reproductive tract was exposed and embryos and parthenotes were transferred into the oviduct (Expts 1 and 3) or uterus (Expt 2) of recipient gilts using a 3.5 french gauge tomcat catheter. In Expt 1, ZI and ZC embryos were 
transferred to contralateral uterine horns of recipient gilts carrying embryos developed to the blastocyst stage, whereas recipient gilts carrying embryos to term received one group or the other. In Expt 2, three blastocysts were transferred to the uterus of recipient gilts that showed signs of oestrus 1 or 2 days after the donor. In the mated recipient group in Expt 2, the recipient gilts were mated and, immediately before embryo transfer, one of the uterine horns was flushed to reduce the number of embryos. Flushing was performed by placing $50 \mathrm{ml}$ media into the tip of the uterine horn via a blunt needle inserted into the oviduct and passed through the uterotubular junction. The medium was then carefully massaged through the uterine horn and collected through a folley catheter inserted previously $6-10 \mathrm{~cm}$ from the bifurcation of the uterus. Corpora lutea were counted on each ovary to select which uterine horn to flush in an attempt to leave at least seven embryos present. The embryos that were being introduced were transferred to the non-flushed uterine horn.

Transfers were carried out in gilts showing signs of either synchronous oestrus in Expts 1 and 3 or asynchronous oestrus (signs of oestrus 1 or 2 days after donor) in Expt 2. Oestrus in recipient gilts was generated either naturally, after superovulation, or synchronization as described for donor gilts. In the first phase of Expt 3, gilts that showed signs of a natural synchronous oestrus (day 2 after oestrus) had between 55 and 60 in vitro matured (IVM) parthenotes transferred to the oviduct on day 1 after activation. In phase II, gilts that exhibited a natural synchronous oestrus had between 55 and 60 IVM parthenotes transferred to the oviduct on day 1 after activation plus three fertilized embryos recovered from gilts mated on the same day as the recipient.

\section{Pregnancy monitoring}

All recipient pigs underwent transabdominal ultrasonography using an Aloka 500 SD ultrasound machine with a $5 \mathrm{MHz}$ convex linear probe between day 21 and day 23 after oestrus.

A result was classed as positive if a fluid-filled area containing a fetal mass could be detected. A negative result was confirmed when no fluid filled areas in the uterus could be detected. Ultrasonography was repeated at regular intervals until term unless two consecutive negative results were obtained at which point the gilt was classed as nonpregnant. In the first phase of Expt 3, ultrasonography was performed twice each week from day 21 after oestrus until the pregnancy was lost. In phase 2, ultrasonography was performed once a week until the pregnancy was lost or delivered at term.

\section{Fetal collection and analysis}

In Expt 2, group $F$ (mated recipients) fetuses were recovered at mid-pregnancy between day 31 and day 94 of gestation. DNA was prepared from fetal tissue samples and from blood collected from the recipient sow, her natural mate and the parents of the transferred embryos to identify fetuses originating from transferred embryos (Miller et al., 1998). Fetal and parental genotypes were determined for nine microsatellite loci (CGA, S0155, S0226, SW240, SW72, SW632, S0101, SW951, SW857) selected from the panel recommended by the Food and Agriculture OrganizationInternational Society for Animal Genetics (FAO-ISAG) for genetic diversity studies in pigs (Laval et al., 2000; http://www. toulouse.inra.fr/lgc/pig/panel.htm). The allelic length variants present at these microsatellite loci were detected by sizing the locus-specific polymerase chain reaction products on an automated DNA sequencer (ABI373). Proprietary software developed by Applied Biosystems (GeneScan ${ }^{\mathrm{TM}}$ and Genotyper ${ }^{\mathrm{TM}}$ ) was used to interpret results.

\section{Hormonal treatments}

In Expt 1, gilts received no treatment after embryo transfer. In Expt 2, gilts in group A received no treatment after embryo transfer; gilts in group B were injected each day from day 11 to day 15 after oestrus with $5 \mathrm{mg}(1 \mathrm{ml})$ oestradiol benzoate (oestradiol benzoate; Intervet UK Ltd); gilts in group $\mathrm{C}$ were injected with $5 \mathrm{mg}(1 \mathrm{ml})$ oestradiol benzoate on day 11 and day 15 after oestrus; gilts in group D were treated with 1200 iu eCG at 09:00 h on day 9 after oestrus and 500 iu hCG at 17:00 h on day 12 after oestrus; and gilts in group $\mathrm{E}$ were treated as those in group $\mathrm{D}$ and were then fed $20 \mathrm{mg}$ altrenogest each day from day 13 after oestrus until confirmed as not being pregnant. In Expt 3, gilts received no treatment after embryo transfer.

\section{Statistical analysis}

In Expt 1, the effects of the type of embryo and culture method (in vivo versus in vitro) used were estimated using restricted maximum likelihood (REML; Patterson and Thompson, 1997) to allow for variation caused by trials, donors, culture wells, recipients or recipient sides. Nonnormal variation between embryos and recipient gilts (that is, binomial variation for proportions and Poisson-type variation for nuclear counts and litter size) was also taken into account by using the method described by Breslow and Clayton (1993). The statistical significance of the effects (in the logistic scale for proportions and in the logarithmic scale for nuclear counts and litter size) was determined approximately using two-tailed Student's $t$ tests with degrees of freedom based on the numbers of trials, donors or recipients available for paired comparisons or on the number of gilts where paired comparisons were not relevant.

\section{Results}

\section{Experiment 1}

In six experimental replicates, the development of $\mathrm{ZI}$ or ZC embryos to the blastocyst stage was assessed after culture in vitro and development in vivo. In total, 85 and 202 embryos were developed in vitro or in vivo, respectively. Of 
Table 1. Summary of paired comparisons of blastocyst development in vitro and in vivo from zona pellucida intact (ZI) and zona pellucida compromised (ZC) pig embryos

\begin{tabular}{|c|c|c|c|c|c|c|}
\hline & \multicolumn{3}{|c|}{$\begin{array}{l}\text { Mean proportion } \\
\text { of blastocysts }\end{array}$} & \multicolumn{3}{|c|}{$\begin{array}{l}\text { Mean nuclear count } \\
\text { of blastocysts }\end{array}$} \\
\hline & $\mathrm{ZI}$ & ZC & Significance & $\mathrm{ZI}$ & ZC & Significance \\
\hline In vitro & 0.58 & 0.75 & $P<0.3$ & 24 & 22 & $P<0.5$ \\
\hline In vivo & 0.58 & 0.60 & $P<0.1$ & 63 & 49 & $P<0.2$ \\
\hline Significance & $P<0.1$ & $P<0.5$ & & $P<0.005$ & $P<0.02$ & \\
\hline
\end{tabular}

aproportion of cleavage stage embryos forming blastocysts, factoring in recovery rates for in vivo developed embryos.

Table 2. Development of zona pellucida intact (ZI) and zona pellucida compromised (ZC) pig embryos to term after transfer to recipient gilts

\begin{tabular}{|c|c|c|c|c|c|c|c|c|}
\hline \multirow[b]{2}{*}{ Replicate } & \multicolumn{4}{|c|}{$\mathrm{ZI}$} & \multicolumn{4}{|c|}{ ZC } \\
\hline & $\mathrm{ET}^{\mathrm{a}}$ & Day $21^{b}$ & $\begin{array}{l}\text { Piglets } \\
\text { farrowed }\end{array}$ & $\begin{array}{l}\text { Live } \\
\text { piglets }\end{array}$ & $\mathrm{ET}^{\mathrm{a}}$ & Day $21^{b}$ & $\begin{array}{l}\text { Piglets } \\
\text { farrowed }\end{array}$ & $\begin{array}{l}\text { Live } \\
\text { piglets }\end{array}$ \\
\hline 1 & 20 & + & 12 & 11 & 20 & & - & \\
\hline \multirow[t]{2}{*}{2} & 20 & - & - & - & 20 & + & 6 & 6 \\
\hline & & & & & 19 & + & 7 & 7 \\
\hline \multirow[t]{2}{*}{3} & 18 & - & - & - & 19 & + & 0 & \\
\hline & 17 & - & - & - & & & & \\
\hline 4 & 20 & + & 6 & 5 & 19 & - & - & - \\
\hline \multirow[t]{2}{*}{5} & 20 & + & 13 & 13 & 20 & - & - & - \\
\hline & 15 & + & 8 & 8 & 20 & + & 5 & 4 \\
\hline \multirow[t]{2}{*}{6} & 20 & + & 13 & 12 & 20 & + & 10 & 10 \\
\hline & & & & & 20 & + & 1 & 0 \\
\hline 7 & 20 & + & 4 & 3 & 20 & - & - & - \\
\hline Total & 170 & 6 & 56 & 52 & 197 & 6 & 29 & 27 \\
\hline
\end{tabular}

aCleavage (two- to four-cell) stage embryos transferred on day 2 of oestrus.

bPregnancy at day 21 assessed by ultrasonography.

ET: embryo transfer.

the embryos cultured in vitro, 42 were $\mathrm{ZI}$ and $43 \mathrm{ZC}$. In the in vivo groups, $104 \mathrm{ZI}$ and $98 \mathrm{ZC}$ embryos were transferred into recipient gilts. In both the in vivo groups, $70 \%$ of the transferred embryos were recovered successfully. Developmental environment had no effect on blastocyst formation of ZI or ZC embryos (Table 1). Micromanipulation had no significant effect on blastocyst formation in vitro or in vivo (Table 1). Similarly, micromanipulation had no effect on blastocyst cell number for embryos developed in vitro. Although there was no significant effect of micromanipulation on blastocyst cell number for embryos developed in vivo (Table 1), it caused an appreciable reduction in blastocyst cell number. Development in vivo improved blastocyst cell number in both ZI and ZC embryos (Table 1).

Seven replicates of embryo transfers were conducted with a total of 19 recipients; nine gilts received ZI embryos and ten gilts received ZC embryos (Table 2). Although six of nine $(67 \%)$ recipients of $\mathrm{ZI}$ embryos were pregnant at day 21 of gestation, six of ten $(60 \%)$ gilts that received ZC embryos were also pregnant. With the exception of one ZC pregnancy, which was no longer detectable by ultrasonography on day 28 , all of these gilts farrowed at term. In total,
$170 \mathrm{ZI}$ embryos and 197 ZC embryos were transferred, resulting in 56 and 29 piglets, respectively. Of these, four $\mathrm{ZI}$ and two ZC piglets were stillborn. Although the proportion of transferred embryos yielding live piglets was lower after micromanipulation, the difference was not significant for the ZI (31\%) and ZC (14\%) groups. There was no difference between $\mathrm{ZI}$ and $\mathrm{ZC}$ groups in live piglet mean litter size or birth weight. Both of these parameters were also comparable with litters obtained from the breeding herd $(n=11)$ during the period of study (Table 3 ).

\section{Experiment 2}

Results of the pregnancy maintenance embryo transfer groups are summarized (Table 4). In group A (control pigs) in which no treatment was given, one gilt of nine was pregnant at day 21, whereas none was pregnant beyond day 35. In group $B$, in which oestradiol was injected each day from day 11 to day 15 of gestation, one gilt of ten became pregnant and maintained the pregnancy to term. This gilt delivered one dead piglet, representing 3\% of transferred embryos. In group C, oestradiol was injected on day 11 and 
Table 3. Development of zona pellucida intact (ZI) and zona pellucida compromised (ZC) pig embryos to term after transfer to recipient gilts

\begin{tabular}{lcccc}
\hline Group & $\begin{array}{c}\text { Number of gilts } \\
\text { yielding live litters }\end{array}$ & $\begin{array}{c}\text { ET success rate } \\
\text { (proportion of ET embryos) }\end{array}$ & $\begin{array}{c}\text { Live litter size } \\
\text { (mean) }\end{array}$ & $\begin{array}{c}\text { Birth weight of live } \\
\text { piglets (mean kg) }\end{array}$ \\
\hline ZI & 6 & $0.31^{\mathrm{a}}$ & $8.5^{\mathrm{b}}$ & $1.54^{\mathrm{b}}$ \\
ZC & 4 & $0.13^{\mathrm{a}}$ & $6.4^{\mathrm{b}}$ & $1.40^{\mathrm{b}}$ \\
Herd & 11 & $\mathrm{NA}$ & 9.8 & 1.41 \\
\hline
\end{tabular}

*Proportion of cleavage stage embryos transferred (see Table 2).

aPaired comparison, $\mathrm{ZI}$ versus $\mathrm{ZC}, P<0.2$.

bPaired comparison, $Z$ I versus ZC, $P<0.5$.

ET: embryo transfer.

Table 4. Efficacy of hormone treatments to maintain pregnancy in non-mated gilts after transfer of three fertile embryos

\begin{tabular}{|c|c|c|c|c|c|c|c|}
\hline Group & Treatment & $\begin{array}{l}\text { Number of } \\
\text { gilts }\end{array}$ & $\begin{array}{c}\text { Pregnant for } \\
>21 \text { days } \\
(\%)\end{array}$ & $\begin{array}{c}\text { Pregnant for } \\
>35 \text { days } \\
(\%)\end{array}$ & $\begin{array}{c}\text { Pregnant } \\
\text { at term }(\%)\end{array}$ & $\begin{array}{l}\text { Piglets born } \\
\text { (number } \\
\text { dead) }\end{array}$ & $\begin{array}{c}\text { Percentage of } \\
\text { added embryos } \\
\text { surviving }\end{array}$ \\
\hline A & None & 9 & $1(11)$ & 0 & 0 & 0 & 0 \\
\hline B & Oestradiol & 10 & $1(10)$ & $1(10)$ & $1(10)$ & $1(1)$ & 3 \\
\hline C & Oestradiol & 19 & $8(42)$ & $6(33)$ & $5(25)$ & $5(1)$ & 9 \\
\hline $\mathrm{D}$ & eCG/hCG & 18 & $7(38)$ & $2(11)$ & $2(11)$ & $4(0)$ & 7 \\
\hline E & eCG/hCG/regumate & 8 & $2(25)$ & 0 & 0 & 0 & 0 \\
\hline
\end{tabular}

day 15 . Of the 19 recipients, eight were pregnant at day 21 , six maintained pregnancy beyond day 35 , and five delivered a total of five piglets at term (one dead), representing $9 \%$ of transferred embryos. In group D, pigs were injected with eCG on day 9 and hCG on day 12 . Of the 18 recipients, seven were pregnant at day 21, two maintained pregnancy beyond day 35, and two delivered a total of four piglets at term (one dead), representing 7\% of transferred embryos. Group $\mathrm{E}$ received the same treatment as group D but altrenogest was fed daily after the hCG injection. Of the eight recipients, two were pregnant at day 21, although none of the recipients maintained pregnancy beyond day 35. The above treatments were directly compared with embryo survival after transfer of three embryos into mated recipients. Of the 18 mated recipients, 18 were pregnant at day 21 and 17 of these recipients maintained pregnancy beyond day 35 . The fetuses were recovered after the gilts were killed on day 94 of pregnancy. The fetuses, the recipient sow and her natural mate as well as the parents of the transferred embryos were genotyped for nine microsatellite markers. Nine gilts (50\%) were found to be carrying fetuses from transferred embryos, and in total 14 (25\%) of the transferred embryos survived.

\section{Experiment 3}

In six replicate trials, 55-60 IVM parthenotes were transferred into 13 gilts on day 2 after oestrus (Table 5). Pregnancy was detected in eight of these gilts by ultrasonography at day 21. Of these, four pregnancies were lost by day 45 and all pregnancies were lost by day 53 . The ability of parthenotes to support a pregnancy after co-transfer with a small number of fertile embryos was investigated. The study consisted of three replicates (Table 6). Between 55 and 60 parthenotes were co-transferred with three fertilized embryos to a total of six non-mated gilts. Of these recipients, four were pregnant at day 21 , one gilt lost the pregnancy at day 45 , one at day 60 and one at day 72 . One gilt maintained pregnancy to term and delivered two live piglets (Fig. 1).

\section{Discussion}

The objective of the present study was to explore methods to sustain limited numbers of viable embryos to term. Immediate transfer of ZC precompacted embryos yielded viable, normal sized litters of piglets, thus minimizing the need to culture embryos to a compacted state. Hormonal supplementation of gilts receiving limited numbers of embryos yielded viable piglets. In addition, the present study is the first to demonstrate a novel pregnancy maintenance alternative involving the co-transfer of parthenogenetic embryos.

Results of the present study indicate that in pigs it is possible to bypass extended embryo culture, or alternatively, agar chipping of micromanipulated embryos, as originally demonstrated in sheep (Willadsen, 1979, 1980). To our knowledge, the first study to suggest that this might be possible in pigs was that of Nagashima et al. (1995), in which delipated cleavage stage embryos were transferred. Assuming that immunological recognition is responsible for the embryonic loss observed by others, delipation may 
Table 5. Developmental competence of parthenogenetic pig embryos: number of pregnancies established and number of days pregnancy was maintained after embryo transfer

\begin{tabular}{lccc}
\hline Replicate & $\begin{array}{c}\text { Number of } \\
\text { transferred } \\
\text { oocytes }\end{array}$ & $\begin{array}{c}\text { Pregnant } \\
21 \text { days }\end{array}$ & $\begin{array}{c}\text { Day of } \\
\text { pregnancy }^{\text {loss }}\end{array}$ \\
\hline 1 & 60 & + & 45 \\
2 & 58 & - & - \\
3 & 60 & - & - \\
4 & 55 & - & - \\
4 & 60 & + & 49 \\
5 & 60 & - & - \\
5 & 60 & + & 53 \\
& 60 & + & 42 \\
6 & 60 & - & - \\
& 59 & + & 39 \\
& 60 & + & 47 \\
\hline
\end{tabular}

aThe day at which a pregnancy was lost was deemed to be the mid-point between the last ultrasound examination when the pregnancy was still visible and the next examination when pregnancy was no longer detected. Examinations were carried out twice each week.

remove a high proportion of antigenic epitopes from the embryo surface. In contrast, in the present study only piercing of the zona pellucida with a large bore pipette was involved without alteration of the membrane surface. Thus, immunological recognition in the reproductive tracts of pigs is either not a critical issue or cleavage stage embryos in this species are at least partially impervious to it.

Overall, there was a reduction in the proportion of ZC embryos developing to term compared with the ZI embryos; however, this difference was not significant. There was also no significant difference in litter or piglet size between groups. Variability in recipient receptivity was a confounding factor in the present study. Of 19 surrogate pigs receiving embryos from either treatment group destined to maintain pregnancy to term, seven (three ZI and four ZC) pigs failed to establish a pregnancy. These failures may be due to the recipient, because in all seven cases the opposite treatment group in each replicate established a pregnancy. In the ZC group, one pregnancy was lost after its establishment, whereas another pregnancy yielded a single stillbirth. These recipients indicate that some degree of embryonic loss was associated with disruption of the zona pellucida, perhaps dependent on individual variability of the recipient. Despite selection of recipients of similar age, weight and time of onset of oestrus, some variability will occur. This variability could be due to a number of uncontrolled factors such as the time between onset of oestrus and ovulation, which is known to vary considerably among pigs (Soede and Kemp, 1997).

Establishment of pregnancy is reduced when transferred embryos are developmentally lagging with respect to the
Table 6. Number of pregnancies established and number of days pregnancy was maintained after co-transfer of parthenogenetic and fertilized pig embryos to six recipients

\begin{tabular}{lccc}
\hline Replicate & $\begin{array}{c}\text { Number of } \\
\text { parthenotes }\end{array}$ & $\begin{array}{c}\text { Number of fertile } \\
\text { embryos }\end{array}$ & $\begin{array}{c}\text { Day of } \\
\text { pregnancy } \\
\text { loss }^{\text {a }}\end{array}$ \\
\hline 1 & 59 & 3 & $\begin{array}{c}\text { Not pregnant } \\
\text { Two live piglets } \\
\text { at term }\end{array}$ \\
2 & 59 & 3 & $72^{\text {a }}$ \\
3 & 60 & 3 & $45^{\text {a }}$ \\
& 60 & 3 & $60^{\text {a }}$ \\
& 60 & 3 & Not pregnant \\
\hline
\end{tabular}

aThe day at which a pregnancy was lost was deemed to be the mid-point between the last ultrasound examination when the pregnancy was still visible and the next examination when pregnancy could no longer be detected. Examinations were carried out twice each week.

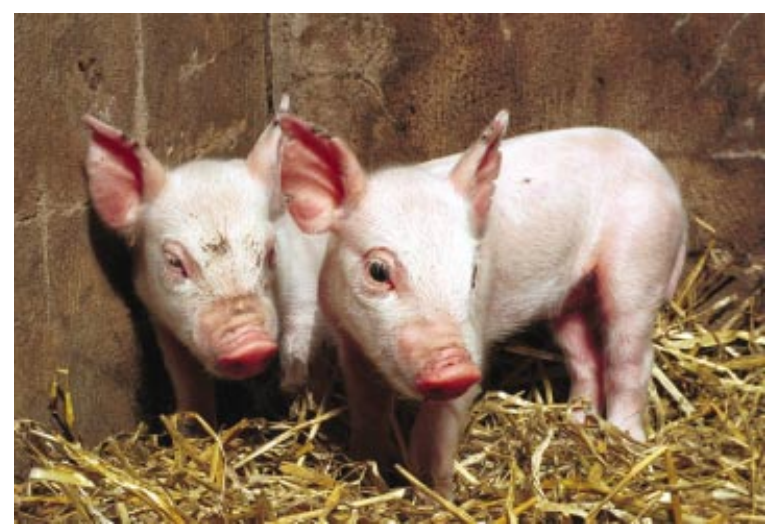

Fig. 1. Two healthy piglets born after co-transfer of three fertilized embryos with 60 parthenogenetic embryos.

oestrous cycle of the recipient (Geisert et al., 1991). This reduction is especially marked after culture under suboptimal conditions (Blum-Reckow and Holtz, 1991). Embryo transfers in our zona pellucida disruption study were synchronous with recipient oestrous cycles, and the duration of culture exposure was minimal (3 h) and equalized between both groups. However, ZC blastocysts developed in vivo did show a reduction in blastocyst nuclear counts relative to the $\mathrm{ZI}$ group, but this result was not significant. This difference was not observed after in vitro culture when numbers of cells were reduced in both groups. After microsurgical blastomere transplantation in pigs, Martin et al. (1991) observed that although in vitro development was not compromised, $50 \%$ of manipulated embryos had reduced development in vivo. Thus, it is possible that early reduction in embryo quality stemming from transfer of ZC precompacted embryos can culminate in later embryonic and fetal loss.

The limitations in the number of viable embryos, such 
as in cloning by nuclear transfer, were addressed by developing strategies to maintain pregnancy after embryo transfer. In the initial experiment, hormonal treatments were tested in a model in which three embryos were transferred into the uterus of non-pregnant recipient gilts before supplementation with oestrogen or stimulation of accessory corpora lutea. These treatments were compared with a group that received three embryos and no hormonal treatment and a second group in which three embryos were transferred into mated recipients and, therefore, already contained a number of fertilized embryos. The present study confirms the results of Polge et al. (1996), which indicated that an untreated recipient with fewer than four viable embryos cannot maintain pregnancy to term. Overall, all four hormonal treatments were successful in establishing pregnancy. In group $E$, in which gonadotrophins were used to establish accessory corpora lutea, the pregnancy rate at day 21 was reasonable (7 of 18, 38\%). However, these pregnancies were not all maintained and only two pregnancies remained at day 35 . This loss after day 21 may have been caused by regression of the accessory set of corpora lutea, which initially would have been refractory to the release of luteolytic agents thought to begin at day 14 of pregnancy. At about day 24 of pregnancy, these corpora lutea would have become sensitive to luteolytic agents. This finding indicates that, in pigs containing limited numbers of fetuses, the release of luteolytic agents continues for longer than normally expected (Frank et al., 1997) or a second pulse occurs. An attempt to circumvent this problem by supplementing recipient gilts with a progestagen at a dose known to extend oestrus (Webel and Day, 1982) was unsuccessful (group E).

The most successful hormonal regimen involved timed injections of oestradiol after which $25 \%$ of gilts maintained pregnancy to term, and 9\% of transferred embryos survived. The timing of these injections was designed to mimic the oestrogen pulses released by embryos in a normal pregnancy which are thought to be an essential mechanism in the maintenance of pregnancy in pigs (Geisert et al., 1990). Although this treatment was reasonably successful in maintaining fertilized embryos to term, such a treatment could be detrimental to developmentally compromised embryos, such as embryos produced or cloned in vitro. Treatment with oestradiol is known to alter the uterine environment (Blair et al., 1991), which may result in death of embryos that are not at the appropriate stage of development (Geisert et al., 1991).

In the present study, mated recipients of embryos were intentionally aborted at various times of gestation to hasten our evaluation of this method. At least $50 \%$ of recipients successfully carried $25 \%$ of transferred embryos. This improvement over hormonal stimulation indicates that maintenance of pregnancy in pigs may require further endocrinological signals than those established during the first 2 weeks of gestation. Although mated recipients may be effective for the transfer of fertilized embryos, developmentally inferior embryos could be disadvantaged in their competition with endogenous embryos for uterine resources. This proposition is supported by recent failed attempts to maintain pig embryos cloned by somatic nuclear transfer in mated recipients (Onishi et al., 2000; Verma et al., 2000).

An alternative approach for maintaining pregnancy using a limited number of viable embryos would be to co-transfer them with supplementary embryos of limited viability. Previous reports indicate that pig parthenotes can develop beyond the critical early period for maternal recognition of pregnancy (Kobayashi et al., 2000; Zhu et al., 2000). In support of this, parthenote pregnancy rates at day 21 of gestation $(8$ of $13,62 \%)$ in the present study were similar to those of the fertilized ZI embryo transfers (ZI, 6 of 9, 67\%). Thus, parthenotes appear to be just as effective as fertilized embryos in producing the correct endocrine signals to maintain pregnancy. In addition we established that parthenotes do not survive in the reproductive tract for more than 55 days.

After co-transfer of three fertilized embryos at the cleavage stage with 55-60 parthenote embryos in Expt 3, two healthy piglets were delivered at term. In contrast, transfer of three blastocyst stage embryos into each of nine untreated recipients in Expt 2 resulted in no pregnancies sustained beyond day 35. Although no control untreated transfers were performed in Expt 3 due to cost and welfare implications, the inability of the same number of more advanced stage embryos to maintain pregnancy would make it unlikely that embryos at an earlier stage of development would be more effective at maintaining pregnancy. Interestingly, two of the recipients of parthenotes and fertilized embryos in Expt 3 carried a pregnancy beyond day 55, further than expected for a parthenote pregnancy. It is not known whether these pregnancies failed as a result of insufficiencies in the pregnancy maintenance strategy or of fetusspecific defects. It is possible that resorptions of parthenotes could have interfered with the maintenance of a viable fetus. This problem could be countered by reducing the number of co-transferred parthenotes. Delaying parthenote transfer until after successful cleavage would allow a more accurate determination of their viability and a better estimate of the optimum number required for successful pregnancy support.

In conclusion, results of the present study indicate that early transfer of micromanipulated embryos in the pig does not prevent successful development, and that hormonal treatments can maintain pregnancies with limited numbers of embryos. In addition, the present study demonstrated for the first time that pregnancies can be established with a mixture of fertilized and parthenote embryos and that fertilized embryos can develop to term successfully. The methods developed in this study have successfully contributed to our somatic cell nuclear transfer programme in the pig (De Sousa et al., in press).

The authors would like to thank A. Ainslie, J. Bowering, J. Bracken, R. Field, H. Findlayson, B. Garth, P. Johnston, C. Marshal, M. Ritchie, M. M. Smith and L. Schreier for technical assistance and kind suggestions. 


\section{References}

Bazer FW, Geisert RD, Thatcher WW and Roberts RM (1982) The establishment and maintenance of pregnancy. In Control of Pig Reproduction pp 227-252 Eds DJA Cole and GR Foxcroft. Butterworth Scientific, London

Betthauser J, Forsburg E, Augenstein M et al. (2000) Production of cloned pigs from in vitro systems Nature Biotechnology 18 1055-1059

Blair RM, Geisert RD, Zavy MT, Yellin T, Fulton RW and Short EC (1991) Endometrial surface and secretory alterations associated with embryonic mortality in gilts administered oestradiol valerate on days 9 and 10 of gestation Biology of Reproduction 44 1063-1079

Blum-Reckow B and Holtz W (1991) Transfer of porcine embryos after 3 days of in vitro culture Journal of Animal Science 69 3335-3342

Breslow NE and Clayton DG (1993) Approximate inference in generalized linear mixed models Journal of the American Statistical Association $\mathbf{8 8}$ 9-25

Bronson RA and McLaren A (1970) Transfer to the mouse oviduct of eggs with and without the zona pellucida Journal of Reproduction and Fertility 22 129-137

Christenson RK and Day BN (1971) Maintenance of unilateral pregnancy in the pig with induced corpora lutea Journal of Animal Science 32 282-286

Collas P and Robl JM (1990) Factors affecting the efficiency of nuclear transplantation in the rabbit embryo Biology of Reproduction 43 877-884

De Sousa PA, Dobrinsky JR, Zhu J et al. Somatic cell nuclear transfer in the pig: control of pronuclear formation and integration with improved methods for activation and maintenance of pregnancy Biology of Reproduction (in press)

Dobrinsky JD, Pursel VG, Long CR and Johnson LA (2000) Birth of piglets after transfer of embryos cryopreserved by cytoskeletal stabilization and vitrification Biology of Reproduction $62564-570$

Dzuik P (1985) Effect of migration, distribution and spacing of pig embryos on pregnancy and fetal survival Journal of Reproduction and Fertility Supplement 33 57-63

Ellicot AR, Dziuk PJ and Polge C (1973) Maintenance of pregnancy in prepubertal gilts Journal of Animal Science 37 971-973

Frank M, Bazer FW, Thatcher WW and Wilcox CJ (1997) A study of prostaglandin $\mathrm{F}_{2}$ as a luteolysin in swine: III. Effects of oestradiol valerate on prostaglandin $\mathrm{F}$, progestins, estrone and estradiol concentrations in the utero-ovarian vein of non-pregnant gilts Prostaglandins 14 1183-1197

Fukui Y, Sawai K, Furudate M, Sato N, Iwazumi Y and Ohsaki K (1992) Parthenogenetic development of bovine oocytes treated with ethanol and cytochalasin B after in vitro maturation Molecular Reproduction and Development 33 357-362

Geisert RD, Zavy MT, Moffat RJ, Blair RM and Yellin T (1990) Embryonic steroids and the establishment of pregnancy in pigs Journal of Reproduction and Fertility Supplement 40 293-305

Geisert RD, Morgan GL, Zavy MT, Blair RM, Gries LK, Cox A and Yellin T (1991) Effect of asynchronous transfer and estrogen administration on survival and development of porcine embryos Journal of Reproduction and Fertility 93 475-481

Geisert RD, Short EC and Zavy MT (1992) Maternal recognition of pregnancy Animal Reproduction Science 28 287-298

Jolliff WJ and Prather RS (1997) Parthenogenic development of in vitro matured, in vivo cultured porcine oocytes beyond blastocyst Biology of Reproduction 56 544-548

Kobayashi S, Miyake M, Okada K and Kato S (2000) Successful implantation of in vitro-matured electro-activated oocytes in the pig Theriogenology 53 1105-1119

Laval G, Iannuccelli N, Legault G et al. (2000) Genetic diversity of eleven European pig breeds Genetic Selection and Evolution 32 187-203
Martin MJ, Cantley TC, Flowers WL and Day BN (1991) Development of porcine embryos following microsurgical blastomere transplantation Animal Reproduction Science 24 315-322

Miller SA, Dykes DD and Polesky HH (1998) A simple salting out procedure for extracting DNA from human nucleated cells Nucleic Acids Research 161215

Modlinski JA (1970) The role of the zona pellucida in the development of mouse eggs in vivo. Journal of Embryology and Experimental Morphology 23 539-547

Moore NW, Adams CE and Rowson LEA (1968) Developmental potential of single blastomeres of the rabbit egg Journal of Reproduction and Fertility $17527-531$

Nagashima H, Kashiwazaki N, Ashman RJ, Grupen CG and Nottle MB (1995) Cryopreservation of porcine embryos Nature 374416

Onishi A, Iwamoto M, Akita T, Mikawa S, Takeda K, Awata T, Hanada H and Perry ACF (2000) Pig cloning by microinjection of fetal fibroblast nuclei Science 289 1188-1190

Patterson HD and Thompson R (1997) Recovery of inter-block information when block sizes are unequal Biometrika 58 545-554

Petters RM and Wells KD (1993) Culture of pig embryos Journal of Reproduction and Fertility Supplement 48 61-73

Polejaeva IA, Shu-Hung C, Vaught TD et al. (2000) Cloned pigs produced by nuclear transfer from adult somatic cells Nature 407 86-90

Polge C, Rowson LEA and Chang MC (1996) The effect of reducing the number of embryos during early stages of gestation on the maintenance of pregnancy in the pig Journal of Reproduction and Fertility 12 395-397

Soede NM and Kemp B (1997) Expression of oestrus and timing of ovulation in pigs Journal of Reproduction and Fertility Supplement 52 91-103

Stice SL and Robl JM (1998) Nuclear reprogramming in nuclear transplant rabbit embryos Biology of Reproduction 39 657-664

Trounson AO and Moore NW (1974) The survival and development of sheep eggs following complete or partial removal of the zona pellucida Journal of Reproduction and Fertility 41 97-105

Verma PJ, Du Z-T, Crocker L, Faast R, Grupen CG, Mcllfatrick SM, Ashman RJ, Lyons IG and Nottle MB (2000) In vitro development of porcine nuclear transfer embryos constructed using fetal fibroblasts Molecular Reproduction and Development 57 262-269

Wang W-H, Abeydeera LR, Prather RS and Day BN (1998) Morphological comparison of ovulated and in vitro matured porcine oocytes, with particular reference to polyspermy after in vitro fertilization Molecular Reproduction and Development 49 308-316

Wang W-H, Abeydeera LR, Han Y-M, Prather RS and Day BN (1999) Morphologic evaluation and actin filament distribution in porcine embryos produced in vitro and in vivo. Biology of Reproduction $\mathbf{6 0}$ 1020-1028

Webel SK and Day BN (1982) The control of ovulation. In Control of Pig Reproduction pp 197-210 Eds DJA Cole and GR Foxcroft. Butterworth Scientific, London

Willadsen SM (1979) A method for the culture of micromanipulated sheep embryos and its use to produce monozygotic twins Nature 211 298-300

Willadsen SM (1980) The viability of early cleavage stages containing half the normal number of blastomeres in the sheep Journal of Reproduction and Fertility 59 357-362

Zhu J, Harkness L, King T, Dobrinsky J, Fletcher J, Telfer E, Wilmut I and De Sousa PA (2000) Fetal development from parthenogenetically activated in vitro matured porcine oocytes Journal of Reproduction and Fertility Abstract Series 25174

Received 19 September 2001.

First decision 15 November 2001.

Accepted 13 December 2001. 